Special Issue of the 8th International Advances in Applied Physics and Materials Science Congress (APMAS 2018)

\title{
Analysis of Air Leakages in Low and Middle-Pressure Self-Flanged Rectangular Cross-Sectional Air Ducts
}

\begin{abstract}
A. Onat*, M.N. Uygun, M. Atmaca And N. GÜnAYtan
Marmara University, Technology Faculty, Department of Mechanical Engineering, İstanbul, Turkey

The air leakages through the air ducts of air conditioning and ventilation systems applied to residential, commercial, and industrial buildings cause higher energy consumption costs, less thermal comfort, and worsening of internal air quality. Also, the leakages affect the design parameters of air conditioning and ventilation systems negatively. The purpose of this study is to experimentally determine the suitable torque strength on the bolt coupling in low and middle pressure self-flanged rectangular cross-sectional air ducts to eliminate air leakages through the bolt couplings. The orifice used during the tests to measure the air leakages was established in accordance with ISO 5167-1:2003 and ISO 5167-2:2003. The inner surface of the tested air ducts is $16.25 \mathrm{~m}^{2}$. In order to figure out the rate of the air leakages in low and middle self-flanged rectangular cross-sectional air ducts, the tests were carried out at the air pressure levels of 100, 300, 500, 700, 900, 1100, 1300, and $1500 \mathrm{~Pa}$ with the torque strengths of $6,8,10,12,14$, and $16 \mathrm{~N}$ m at each pressure levels with and without $\mathrm{G}$ clamps. As a result, the most appropriate torque strength values on the bolt coupling, depending upon air pressures, were determined experimentally in the low and middle pressure air ducts. The minimum air leakages rates are obtained at torque strengths of $8 \mathrm{~N}$ m with $\mathrm{G}$ clamps.
\end{abstract}

DOI: 10.12693/APhysPolA.135.632

PACS/topics: air duct, air leakage, pressure, torque strengths, self-flanged, G clamps

\section{Introduction}

There are a wide range of components which constitute of a central heating, ventilating, and air conditioning (HVAC) duct system that is a branching network of circular, rectangular, and elliptical (oval) tubes produced from sheet metal, fibreglass board or a flexible plastic and wire composite. These components are dampers, turning vanes, variable-air-volume (VAV) control units, duct type heating cooling coils (DTHCC), supply and return registers, and sensors for temperature, humidity, smoke, carbon dioxide concentration, pressure, and flow rate [1]. Any study and research of an air conditioning system applied to residential, commercial, industrial, and healthcare buildings should be focused mainly on energy losses contributed by air leakages in addition to indoor air quality, thermal comfort, micro-organisms, pressures, sustainability, and environmental protection. An increase in leakages air ducts leads to an increase in fan load, thus fan power consumption [2]. In various investigations and studies, it is highlighted that energy loss due to the air leakage in air handling unit's (AHU) and ducts is at a considerable level. The duct systems used especially in office, large commercial and industrial buildings, and dwellings leak air substantially, owing to inadequate ductwork and ill-fitted components, insufficient sealing work, worn tapes, and physical damage during maintenance, etc. [3].

Although air leakage is a fundamental problem in ducts, the necessity of decreasing leakages is not really

*corresponding author; e-mail: ayhanonat@marmara.edu.tr realized commonly. The redundant energy use related to the air leakage occurs with the need for extra air supplied by fan to recover the amount of air leaked. An increase in leakages leads to an increase in fan load, thus fan power consumption [4]. Liddament et al. [3] have investigated the implication of duct leakage; a field study was performed on 42 duct systems in Belgium and France. Their study shows that the air leakage rate appears to be typically three times greater than the maximum air leakage limit highlighted in EUROVENT 2 (Class A). Ozerdem et al. [1] have analyzed the effect of air leakage on energy wastage. In their experiments it is indicated that the leakage from the joint surfaces and corners, up to $92 \%$ for circular and $86 \%$ for rectangular ducts, has the highest share in total air leakage. In addition, seam leakage has also a significant share in total leakages with up to $13 \%$ for circular and $20 \%$ for rectangular ducts. One solution which has been suggested to decrease leakages is using sealing gaskets. Fisk et al. [4] investigated air leakages of duct systems in large commercial buildings. In their research, it is underlined that the energy losses of ducts are triggered by both air leakage and conduction. In addition to this, the estimated air leakage rates in supply duct systems as a percentage of the inlet air flow rate are in the range of $0 \%$ to $30 \%$. Canbaz et al. [5] investigated the amount of the air leakages, the root of the leakages, and certain leakage zones in duct type heating cooling coils. To define the amount of leakages and leakage zones, they first performed the tests on a reference coil at the average test pressures of 400, 800, 1200, 1600, and $2000 \mathrm{~Pa}$. Enhancements were made on the reference coil alternately and the reference coil has been re-tested. Then, the effect of the enhancements is compared to the reference results. 


\section{Materials and method}

\subsection{Orifice plate air leakage test rig}

Proctor et al. [6] and Srinivasan [7] indicated that various methods of testing have been used in order to measure the air leakages in ducts. Srinivasan [7] also suggested that the most accurate and sensitive method of air leakage measurement is the orifice method. Moreover, to measure air leakages for the purpose of scientific research and define acceptable values in the standards in air leakages of ducts, orifice plate method is widely used. Orifice plates which have a fixed geometry are also the most popular flow meters in fluid flow measurement, especially in oil and gas industry. Being simple, easy to produce, and having high accuracy are advantageous for them against their competitors [8]. As it proved qualitative way of testing, orifice flow method has been chosen for the air leakage measurement of coils. Air leakage test rig is established in reference to EN 5167-1, EN 1751-2, and SMACNA (HVAC Air Duct Leakage Test Manual). For calculation of mass flow and pressure drop measurement method EN 1886, EN 15727:2010 are considered as well as SMACNA [9-14]. According to the standards of EN 15727:2010 and DW 144, each test pressure must be kept within $\pm 5 \%$ of the specified test pressure at least for $5 \mathrm{~min}[15,16]$. In this research, this rate has been tried to be maintained within $\pm 2 \%$ as much as possible. Due to the effect of the test pressure corresponding to the estimation is nearly zero. Orifice plate is designed and manufactured with reference to ISO 5167 standard. Measurement of air leakage and calculation of the leakage rates were performed using the standards of EN 15727:2010, TS EN 1751:2002, ISO 5167-1:2003, and ISO 5167-2:2003.

Orifice meter air metering system consists of EC fan, flow regulator, orifice plate, two digital differential pressure gauges, and two calibration gauges for calibrating the differential pressure gauge. The EC centrifugal fan with code EBM G1G170-AB53-03 was used in the measurement setup. This fan is speed controlled and has a single inlet with backward curved blades. In ISO 5167-1 2003 standard flow regulators with different geometric structures are proposed. The geometry of the flow regulator is important in terms of performance, efficiency, and pressure losses at the inlet and outlet of the plate. In this study, NEL (Spearman) flow regulator recommended in ISO 5167-1 2003 was selected and manufactured. The front and back surfaces of the orifice plate are designed flat and smooth. The geometry of the internal diameters of the orifice plate is suitable for the definition in ISO 5167 standard.

Two differential pressure transmitters (Dwyer) having $1 \%$ of accuracy and $1 \%$ stability were used to measure the differential pressure in the orifice meter and the duct in the test setup. The measurement ranges of the MS311-LCD series instrument used in the orifice meter are 0-250, 0-500, and 0-1250 $\mathrm{Pa}$, and the measurement range of the MS-341-LCD series transmitter used to measure the duct differential pressure is $0-3000 \mathrm{~Pa}$. Calibration of both differential pressure transmitters was made with $\mathrm{U}$ manometers used in the system. In Fig. 1, orifice plate air leakage test rig and test set up are shown. The setup consists of air ducts having rectangular crosssection area with a self-flanged inner surface contact area of approximately $16.25 \mathrm{~m}^{2}$. The air ducts have been suspended on ceiling by means of steel anchors and stud bolts to simulate real conditions. Tightening (bolt + nut) at duct connection points is done with torque meter running at 3-30 $\mathrm{N}$ m torque range with accuracy of \pm 2.5 . All four bolts are tightened with the same torque. The sheet metal thickness of the ducts is $0.80 \mathrm{~mm}$. The G-clamp connections were made at $150 \mathrm{~mm}$ intervals [14].

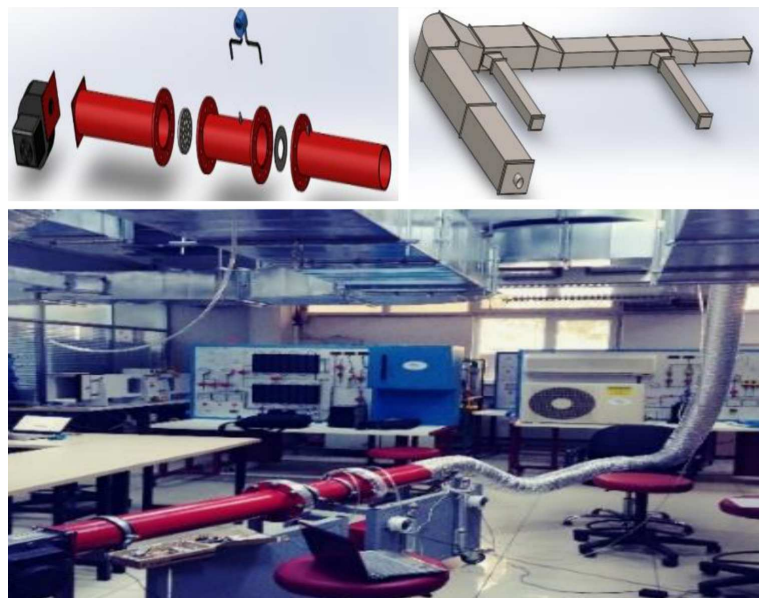

Fig. 1. Orifice plate air leakage test rig and test setup.

\subsection{Calculating air leakages}

The principle of the method of measurement is based on the installation of an orifice plate into a pipeline in which a fluid is running full. The presence of the orifice plate causes a static pressure difference between the upstream and downstream sides of the plate. The mass flow rate, $q_{m}(\mathrm{~kg} / \mathrm{s})$ can be determined using Eq. (1) [10]:

$$
q_{m}=\frac{C}{\sqrt{1-\beta^{4}}} \varepsilon \frac{\pi}{4} d^{2} \sqrt{2 \Delta P \rho_{1}} .
$$

In Eq. (1), $q_{m}$ is mass flow rate, $C$ is discharge coefficient, $\varepsilon$ - expansion factor, and $\beta$ is a constant which is the ratio of orifice inner diameter $d$ to the tube's inner surface diameter $D$. It is calculated as follows: $\beta=\frac{50.4}{130}=0.387$. The density of air during the tests $(\rho)$ is $1.204 \mathrm{~kg} / \mathrm{m}^{3}$ at an ambient temperature of $20^{\circ} \mathrm{C} . \Delta P$ is the pressure difference between the orifice surfaces. If $D>71.12 \mathrm{~mm}$, the discharge coefficient $C$ is given by the Reader-Harris/Sattary [17] Eq. (2):

$$
C=0.5961+0.0261 \beta^{2}-0.216 \beta^{8}+0.000521\left(\frac{10^{6} \beta}{\operatorname{Re}_{D}}\right)^{0.7}
$$


TABLE I

$$
\begin{aligned}
& +(0.0188+0.0063 A) \beta^{3.5}\left(\frac{10^{6}}{\operatorname{Re}_{D}}\right)^{0.3} \\
& +\left(0.043+0.080 e^{-10 L_{1}}-0.123 e^{-7 L_{1}}\right)(1-0.11 A) \\
& \times \frac{\beta^{4}}{1-\beta^{4}}-0.031\left(M_{2}^{\prime}-0.8 M_{2}^{\prime 1,1}\right) \beta^{1.3}
\end{aligned}
$$

In Eq. (2), Re is the Reynolds number at tube inner surface, $\operatorname{Re}_{D}=\frac{V_{1} D}{\vartheta}$, where $V_{1}$ is the air velocity, $\vartheta$ is the kinematic viscosity. Additionally, $A=\left(\frac{19000 \beta}{\operatorname{Re}_{D}}\right)^{0.8}$, $L_{1}=\frac{l_{1}}{D}, L_{2}=\frac{l_{2}}{D}, M_{2}^{\prime}=\frac{2 L_{2}}{1-\beta}$ and according to the standard, front and rear orifice fittings distances are $D$ and $\frac{D}{2}$, respectively and therefore, $L_{1}=1$ and $L_{2}=0.47 \mathrm{~m}$. Finally, expansion factor is calculated [10] as presented in Eq. (3):

$$
\varepsilon=1-\left(0.351+0.256 \beta^{4}+0.93 \beta^{8}\right)\left[1-\left(\frac{P_{2}}{P_{1}}\right)^{\frac{1}{K}}\right],
$$

where $P_{1}$ and $P_{2}$ are the pressures measured from the front and rear side of the orifice, respectively. Also, $K$ is calculated as follows: $K=\frac{C_{p}}{C_{V}}=1.4$. Computation of the mass flow rate, which is a purely arithmetic process, can be performed by replacing the different terms on the right hand side of the basic Eq. (1) by their numerical values. Similarly, the value of volume flow rate $q_{v}(\mathrm{l} / \mathrm{s})$ is calculated from Eq. (4):

$$
q_{v}=\frac{q_{m}}{\rho}
$$

where $\rho$ is the fluid density at the temperature and pressure for which the volume is stated. $f\left(1 /\left(\mathrm{s} \mathrm{m}^{2}\right)\right)$ is air leakage rate, $q_{v}$ is volume flow converted to $\mathrm{l} /\left(\mathrm{s} \mathrm{m}^{2}\right)$. $A\left(\mathrm{~m}^{2}\right)$ is area of inner surface duct. Air leakage rate is calculated by means of Eq. (5):

$$
f=\frac{q_{v}}{A} \text {. }
$$

Decrease in leakages as percentage (\%) are calculated by means of Eq. (6):

decrease in air leakages $(\%)=$

$$
\frac{f_{\text {with GC }}-f_{\text {without GC }}}{f_{\text {with GG }}} \times 100 \text {. }
$$

\section{Findings and discussion}

Tests were carried out the rate of the air leakages in low and middle self-flanged rectangular cross-sectional air ducts, and they were carried out at the air pressure levels of $100,300,500,700,900,1100,1300$, and $1500 \mathrm{~Pa}$ with the torque strengths of $6,8,10,12,14$, and $16 \mathrm{~N} \mathrm{~m}$ at each pressure levels with and without $\mathrm{G}$ clamps. All four bolts were tightened with the same torque. The sheet metal thickness of the ducts was $0.80 \mathrm{~mm}$. The G-clamp

\begin{tabular}{|c|c|c|c|c|}
\hline \multirow[t]{2}{*}{$\begin{array}{c}\text { Test } \\
\text { pressure } \\
{[\mathrm{Pa}]}\end{array}$} & \multirow[t]{2}{*}{$\begin{array}{c}\text { Torque } \\
\text { strength } \\
\text { [N m] }\end{array}$} & \multicolumn{2}{|c|}{$\begin{array}{c}\text { Rate of the } \\
\text { air leakages } \\
\text { air ducts }\left[1 /\left(\mathrm{s} \mathrm{m}^{2}\right)\right]\end{array}$} & \multirow[t]{2}{*}{$\begin{array}{c}\text { Decrease } \\
\text { in the air } \\
\text { leakage [\%] }\end{array}$} \\
\hline & & Without G & With G & \\
\hline \multirow{6}{*}{100} & 6 & 0.38 & 0.26 & 31.58 \\
\hline & 8 & 0.35 & 0.22 & 37.14 \\
\hline & 10 & 0.41 & 0.29 & 29.27 \\
\hline & 12 & 0.41 & 0.26 & 36.59 \\
\hline & 14 & 0.45 & 0.29 & 35.56 \\
\hline & 16 & 0.50 & 0.32 & 36.00 \\
\hline \multirow{6}{*}{300} & 6 & 0.52 & 0.31 & 40.38 \\
\hline & 8 & 0.50 & 0.31 & 38.00 \\
\hline & 10 & 0.52 & 0.34 & 34.62 \\
\hline & 12 & 0.52 & 0.32 & 38.46 \\
\hline & 14 & 0.55 & 0.35 & 36.36 \\
\hline & 16 & 0.58 & 0.38 & 34.48 \\
\hline \multirow{6}{*}{500} & 6 & 0.58 & 0.38 & 34.48 \\
\hline & 8 & 0.57 & 0.36 & 36.84 \\
\hline & 10 & 0.59 & 0.39 & 33.90 \\
\hline & 12 & 0.59 & 0.39 & 33.90 \\
\hline & 14 & 0.61 & 0.41 & 32.79 \\
\hline & 16 & 0.64 & 0.44 & 31.25 \\
\hline \multirow{6}{*}{700} & 6 & 0.69 & 0.44 & 34.48 \\
\hline & 8 & 0.63 & 0.41 & 36.84 \\
\hline & 10 & 0.65 & 0.44 & 33.90 \\
\hline & 12 & 0.65 & 0.46 & 33.90 \\
\hline & 14 & 0.68 & 0.48 & 32.79 \\
\hline & 16 & 0.71 & 0.51 & 31.25 \\
\hline \multirow{6}{*}{900} & 6 & 0.76 & 0.49 & 35.53 \\
\hline & 8 & 0.70 & 0.47 & 32.86 \\
\hline & 10 & 0.72 & 0.50 & 30.56 \\
\hline & 12 & 0.72 & 0.51 & 29.17 \\
\hline & 14 & 0.74 & 0.53 & 28.38 \\
\hline & 16 & 0.76 & 0.57 & 25.00 \\
\hline \multirow{6}{*}{1100} & 6 & 0.82 & 0.54 & 34.15 \\
\hline & 8 & 0.75 & 0.52 & 30.67 \\
\hline & 10 & 0.77 & 0.54 & 29.87 \\
\hline & 12 & 0.77 & 0.56 & 27.27 \\
\hline & 14 & 0.79 & 0.59 & 25.32 \\
\hline & 16 & 0.82 & 0.62 & 24.39 \\
\hline \multirow{6}{*}{1300} & 6 & 0.87 & 0.62 & 28.74 \\
\hline & 8 & 0.82 & 0.57 & 30.49 \\
\hline & 10 & 0.82 & 0.62 & 24.39 \\
\hline & 12 & 0.82 & 0.64 & 21.95 \\
\hline & 14 & 0.84 & 0.67 & 20.24 \\
\hline & 16 & 0.87 & 0.69 & 20.69 \\
\hline \multirow{6}{*}{1500} & 6 & 0.89 & 0.69 & 22.47 \\
\hline & 8 & 0.87 & 0.65 & 25.29 \\
\hline & 10 & 0.88 & 0.71 & 19.32 \\
\hline & 12 & 0.88 & 0.73 & 17.05 \\
\hline & 14 & 0.89 & 0.75 & 1573 \\
\hline & 16 & 0.92 & 0.85 & 7.61 \\
\hline
\end{tabular}
connections were made at $150 \mathrm{~mm}$ intervals.

Air leakage rates were calculated. The leakage rates were calculated using Eqs. (1)-(5) in terms of $\mathrm{l} /\left(\mathrm{s} \mathrm{m}^{2}\right)$ and presented in Fig. 2 and Table I. Figure 2 shows
Test pressure, torque strength, and rate of the air leakages air ducts. 

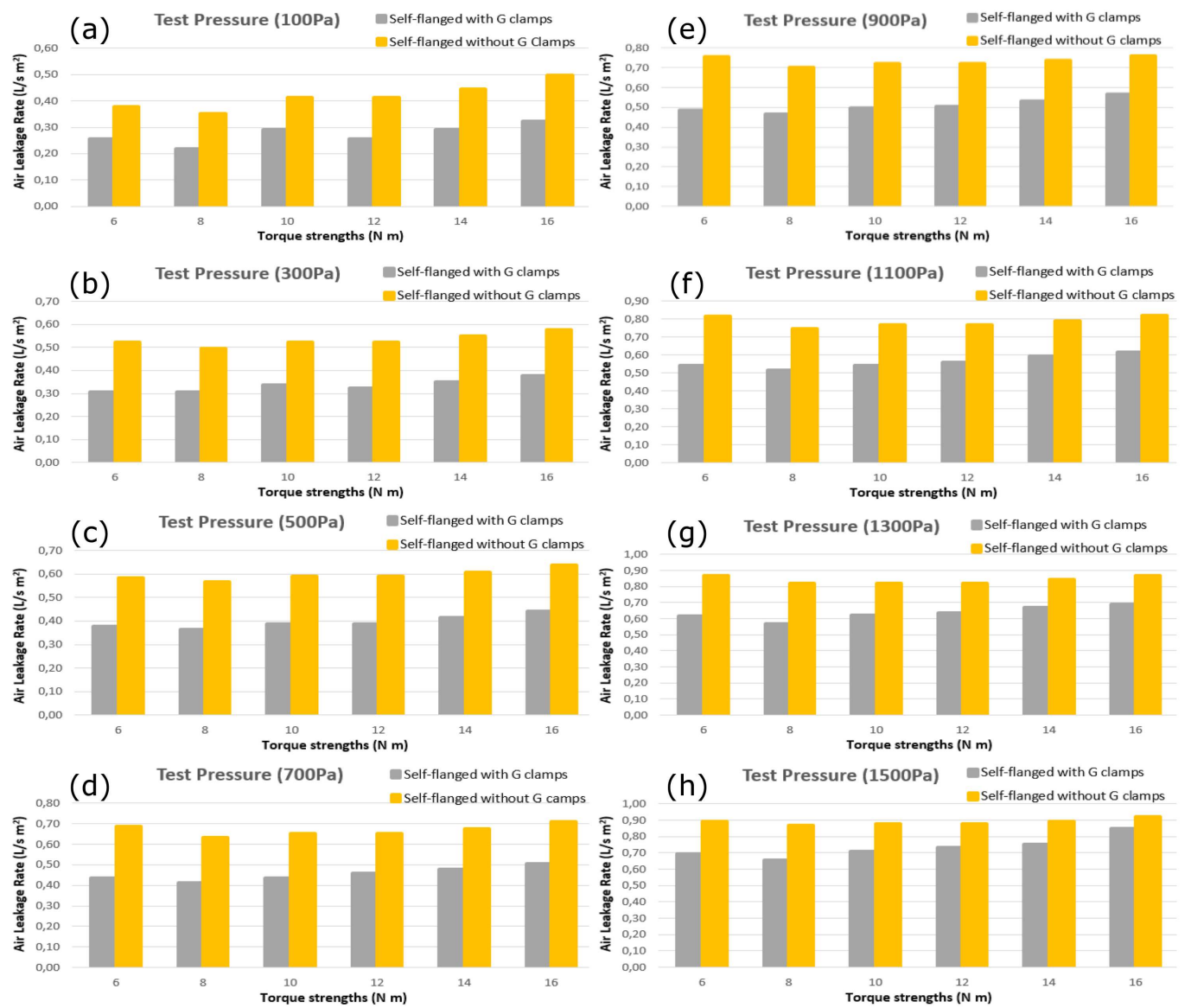

Fig. 2. Rate of the air leakages self-flanged rectangular air ducts. Test pressure: (a) $100 \mathrm{~Pa}$, (b) $300 \mathrm{~Pa}$, (c) $500 \mathrm{~Pa}$, (d) $700 \mathrm{~Pa}$, (e) $900 \mathrm{~Pa}$, (f) $1100 \mathrm{~Pa}$, (g) $1300 \mathrm{~Pa}$, (h) $1500 \mathrm{~Pa}$.

the leakage rates for low and middle pressure rectangular ducts as 100, 300, 500, 700, 900, 1100, 1300, $1500 \mathrm{~Pa}$ and $6,8,10,12,14$, and $16 \mathrm{~N} \mathrm{~m}$. In all cases, as the duct pressure increases, the leakage rate increases. At all pressures and torques, air leakage rates of the $\mathrm{G}$ clamps-on connections is lower than the without G clamps connections as expected. The lowest air leakage in relation to duct pressure levels was calculated to be $0.22 \mathrm{l} /\left(\mathrm{s} \mathrm{m}^{2}\right)$ for clip-on connection for $100 \mathrm{~Pa}$ pressure and $8 \mathrm{~N}$ m torque, while $0.92 \mathrm{l} /\left(\mathrm{s} \mathrm{m}^{2}\right)$ for clipless connection for highest air leakage rate of $1500 \mathrm{~Pa}$ pressure and $16 \mathrm{~N}$ m torque. The optimal torque value is $8 \mathrm{~N} \mathrm{~m}$ for air ducts with a sheet metal thickness of $0.80 \mathrm{~mm}$ and aspect of $60 \times 45 \mathrm{~mm}$ and smaller. In $100 \mathrm{~Pa}$ test pressure, the lowest leakage rate is found at $8 \mathrm{~N} \mathrm{~m}$ torque. The leakage rate, under $8 \mathrm{~N} \mathrm{~m}$ torque, is calculated as $0.35 \mathrm{l} /\left(\mathrm{s} \mathrm{m}^{2}\right)$ and $0.22 \mathrm{l} /\left(\mathrm{s} \mathrm{m}^{2}\right)$ for the connections with and without $G$ clamps, respectively.

The highest leakage rate is found at $16 \mathrm{~N}$ m torque. At $500 \mathrm{~Pa}$ test pressure, the leakage is found to be $0.57 \mathrm{l} /\left(\mathrm{s} \mathrm{m}^{2}\right)$ in connections without $\mathrm{G}$ clamps, where as it is $0.36 \mathrm{l} /\left(\mathrm{s} \mathrm{m}^{2}\right)$ for the connections with $\mathrm{G}$ clamps. At $500 \mathrm{~Pa}$, the highest leakage rates are found to be 0.64 and $0.44 \mathrm{l} /\left(\mathrm{s} \mathrm{m}^{2}\right)$ for connections with and without $\mathrm{G}$ clamps, respectively. At $1100 \mathrm{~Pa}$ test pressure, the leak- age rate is calculated as $0.75 \mathrm{l} /\left(\mathrm{s} \mathrm{m}^{2}\right)$ for connections without $\mathrm{G}$ clamps, whereas it is $0.75 \mathrm{l} /\left(\mathrm{s} \mathrm{m}^{2}\right)$ for connections with $\mathrm{G}$ clamps. At $1500 \mathrm{~Pa}$ and $8 \mathrm{~N} \mathrm{~m}$ torque, with the highest test pressure applied, the leakage rate is found as $0.87 \mathrm{l} /\left(\mathrm{s} \mathrm{m}^{2}\right)$ for the connections without $\mathrm{G}$ clamps, while it is $0.65 \mathrm{l} /\left(\mathrm{s} \mathrm{m}^{2}\right)$ for the connections with $\mathrm{G}$ clamps. The highest leakage rates are calculated at $16 \mathrm{~N} \mathrm{~m}$ torque value as $0.85 \mathrm{l} / \mathrm{s} \mathrm{m}^{2}$ and $0.92 \mathrm{l} /\left(\mathrm{s} \mathrm{m}^{2}\right)$ for connections with and without $\mathrm{G}$ clamps, respectively. The bolts in the four corners must be tightened with the same torque. It is predicted that tightening the different corners with different torque values results in increase of the resulting air leakage rate.

\section{Conclusion}

At all pressures and torques, air leakage rates of the $G$ clamps-on connection are lower than without $\mathrm{G}$ clamps connections as expected. The minimum air leakage rates are obtained at torque strengths of $8 \mathrm{~N} \mathrm{~m}$ with $\mathrm{G}$ clamps each air duct pressure levels of 100, 300, 500, 700, 900, 1100,1300 , and $1500 \mathrm{~Pa}$. The lowest air leakage in relation to duct pressure levels is calculated to be $0.22 \mathrm{l} / \mathrm{cm}^{2}$ for clip-on connection for $100 \mathrm{~Pa}$ pressure and $8 \mathrm{~N} \mathrm{~m}$ torque, while $0.92 \mathrm{l} / \mathrm{cm}^{2}$ for clip less connection for 
highest air leakage rate of $1500 \mathrm{~Pa}$ pressure and $16 \mathrm{~N} \mathrm{~m}$ torque. As the duct test pressure value increases, the difference between air leakage rate between the clip-on and the clip less connection is reduced for all torque values. In all cases, as the duct pressure increases, the leakage rate increases.

The optimal torque value is $8 \mathrm{~N} \mathrm{~m}$ for air ducts with a sheet metal thickness of $0.80 \mathrm{~mm}$ and aspect of $60 \times 45 \mathrm{~mm}$ and smaller. It is predicted that tightening the different corners with different torque values cause increase in the resulting air leakage rate. Additional study should be made on this subject. The optimal torque value may vary as duct aspect ratio and sheet metal thickness change. Experiments with different aspect ratio and sheet metal thicknesses should be conducted.

\section{Acknowledgments}

Financial support for this study by the research fund of the Marmara University under Grant No BAPKO FENC-YLP-FEN-C-YLP-130612-0227 is gratefully acknowledged. We also would like to thank ISIDEM A.Ş. for their support in manufacturing and installation of air ducts.

\section{References}

[1] Ç. Aydin, B. Özerdem, Energy Build 38, 207 (2006).

[2] U. Herman, B. Kelly, H. Price, Appl. Therm. Eng. 23, 251 (2003).

[3] F.R. Carrie, A. Bossaer, J.V. Andersson, P. Wouters, M. Liddament, Energy Build 32, 235 (2000).

[4] W.J. Fisk, W. Delp, R. Diamond, D. Dickerhoff, R. Levinson, M. Modera, M. Nematollahi, D. Wang, Energy Build 32, 109 (2000).
[5] H. Canbaz, E. Söylemez, A. Onat, Energy Sci. Res. 31, 79 (2013).

[6] J.M.B. Proctor, "Diagnosing Ducts", Home Energy Mag. Online, 1993.

[7] K. Srinivasan, Energy Build 37, 273 (2005).

[8] S. Beck, J. Mazille, Flow Meas. Instrum. 165, 379 (2002).

[9] ISO 5167-1:2003, Measurement of fluid flow by means of pressure differential devices inserted in circular cross-section conduits running full - Part 1: General principles and requirements, 2003.

[10] ISO 5167-2:2003, Measurement of fluid flow by means of pressure differential devices inserted in circular cross-section conduits running full — Part 2: Orifice plates, 2003.

[11] BS EN 1507:2006, Ventilation for buildings - Sheet metal air ducts with rectangular section - Requirements for strength and leakage, 2006.

[12] EN1886, Ventilation for buildings - Air handling units - Mechanical performance, 2003.

[13] Eurovent 2/2, Air Leakage Rate in Sheet Metal, Air Distribution Systems, 1996.

[14] SMACNA, HVAC Air Duct Leakage Test Manual, 1985.

[15] EN 15727:2010 Ventilation for buildings — Ducts and ductwork components - leakage classification and testing.

[16] DW/143, Handbook of Ductwork Leakage Testing, 2000.

[17] M.J. Reader-Harris, J.A. Sattary, in: Proc. 14th North Sea Flow Measurement Workshop, Glasgow 1996, National Engineering Laboratory, p. 24. 